\title{
EBER2 RNA-induced transcriptome changes identify cellular processes likely targeted during Epstein Barr Virus infection Sebastian Eilebrecht ${ }^{\dagger 1}$, François-Xavier Pellay ${ }^{\dagger 2}$, Peter Odenwälder ${ }^{1}$, Guillaume Brysbaert ${ }^{2}$, Bernd-Joachim Benecke ${ }^{1}$ and Arndt Benecke*2
}

\author{
Address: ${ }^{1}$ Department of Biochemistry; Ruhr University Bochum; Universitätsstr, 150; 44780 Bochum; Germany and ${ }^{2}$ Institut des Hautes Études \\ Scientifiques \& Institut de Recherche Interdiciplinaire - CNRS USR3078 - Université Lille1; 35, route de Chartres; 91440 Bures sur Yvette; France \\ Email: Sebastian Eilebrecht - sebastian.eilebrecht@ruhr-uni-bochum.de; François-Xavier Pellay - fpellay@ihes.fr; \\ Peter Odenwälder - peter.odenwaelder@rub.de; Guillaume Brysbaert - brysbaert@ibl.fr; Bernd-Joachim Benecke - bernd- \\ joachim.benecke@ruhr-uni-bochum.de; Arndt Benecke* - arndt@ihes.fr \\ * Corresponding author †Equal contributors
}

Published: 28 October 2008

BMC Research Notes 2008, I:100 doi:10.1 186/1756-0500-1-100
Received: 2 August 2008

Accepted: 28 October 2008

This article is available from: http://www.biomedcentral.com/I756-0500/I/I00

(c) 2008 Benecke et al; licensee BioMed Central Ltd.

This is an Open Access article distributed under the terms of the Creative Commons Attribution License (http://creativecommons.org/licenses/by/2.0), which permits unrestricted use, distribution, and reproduction in any medium, provided the original work is properly cited.

\begin{abstract}
Background: Little is known about the physiological role of the EBERI and 2 nuclear RNAs during Epstein Barr viral infection. The EBERs are transcribed by cellular RNA Polymerase III and their strong expression results in $10^{6}$ to $10^{7}$ copies per EBV infected cell, making them reliable diagnostic markers for the presence of EBV. Although the functions of most of the proteins targeted by EBER RNAs have been studied, the role of EBERs themselves still remains elusive.
\end{abstract}

Findings: The cellular transcription response to EBER2 expression using the wild-type and an internal deletion mutant was determined. Significant changes in gene expression patterns were observed. A functional meta-analysis of the regulated genes points to inhibition of stress and immune responses, as well as activation of cellular growth and cytoskeletal reorganization as potential targets for EBER2 RNA. Different functions can be assigned to different parts of the RNA.

Conclusion: These results provide new avenues to the understanding of EBER2 and EBV biology, and set the grounds for a more in depth functional analysis of EBER2 using transcriptome activity measurements.

\section{Findings \\ Background}

Epstein-Barr virus (EBV) is a member of the herpesvirus family present in almost the entire human adult population [1-3] and has been found to be associated with oncogenesis of Burkitt's lymphoma, B- and T-cell leukemia/ lymphomas, nasopharyngeal carcinoma, breast cancer and gastric cancer [4-7]. In EBV infected cells, several viral genes are expressed of which the six nuclear antigens (EBNAs 1-6), the three membrane proteins (LMP-1, -2A and $-2 \mathrm{~B}$ ) and the small non translated EBER1 and EBER2 RNAs are the most abundant $[1,3]$.

The EBERs are transcribed by cellular RNA Polymerase III (polIII) and their strong expression results in $10^{6}$ to $10^{7}$ copies per EBV infected cell $[8,9]$, making them reliable diagnostic markers for the presence of EBV. EBERs are located in the nucleus [10] and have been shown to bind to several cellular proteins, such as the La antigen $[9,11$ $14]$, the EBER-associated protein (EAP, now referred to as 
ribosomal protein L22) [15,16], and the interferon-inducible protein kinase $\mathrm{R}$ (PKR) $[17,18]$. The binding of EBER1 to PKR blocks the PKR pathway resulting in the resistance of the cell to Fas-mediated apoptosis [19]. Although the functions of most of the proteins targeted by EBER RNAs have been studied, the role of EBERs themselves still remains elusive.

EBER-induced interleukin (IL)-10 expression in Burkitt's lymphoma (BL) cells has been demonstrated [20]. IL-10 is suggested to be an autocrine growth factor for BL cells [21], and hence potentially links EBER expression to hyperplastic transformation. Furthermore, a recent report indicates that rather EBER2 than EBER1 plays a central role in B-cell growth transformation [22]. Given this indication of a transcriptional response to EBER expression, as well as the indication of the functional implication of EBER2 in cellular transformation, we used microarrays to
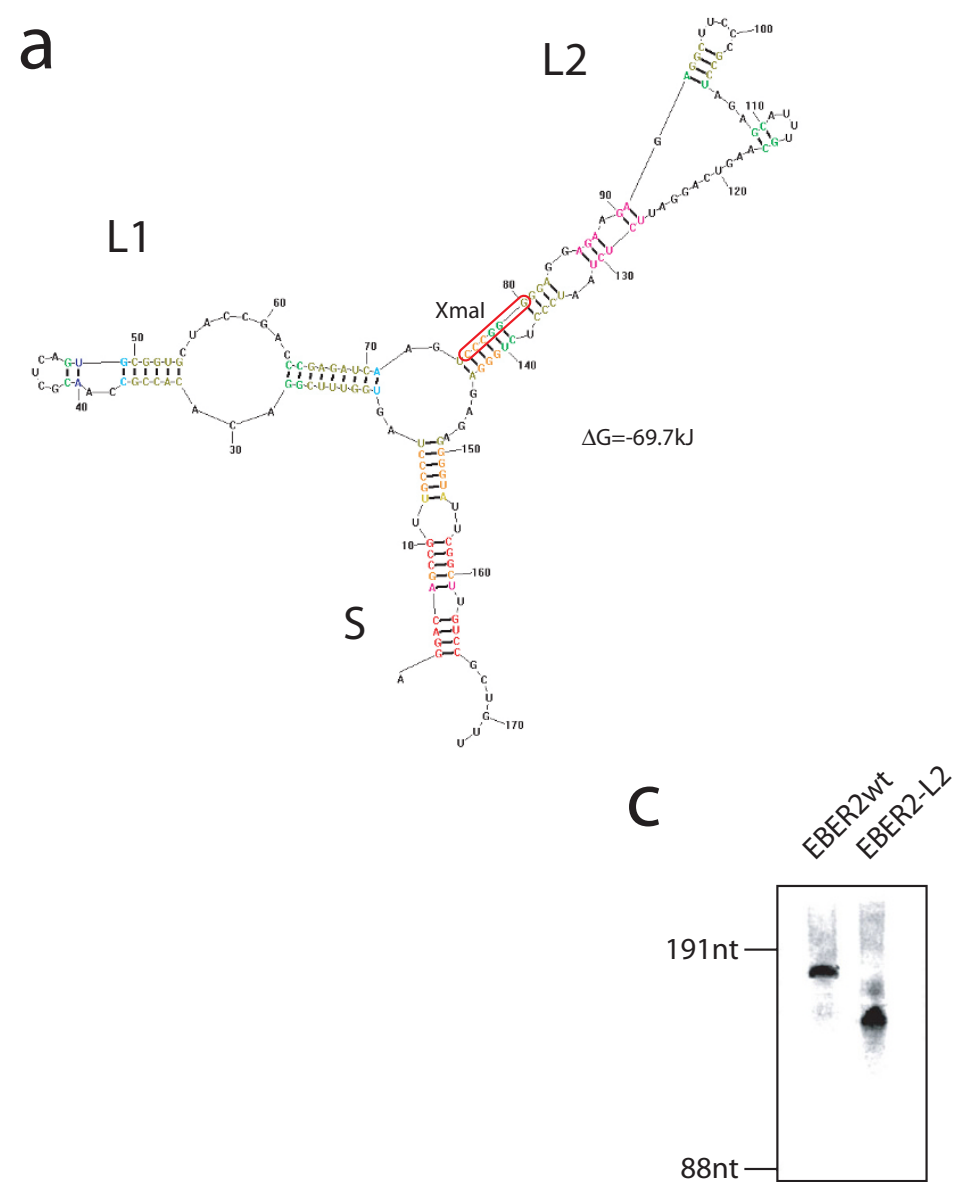

\section{Figure I}

a. Predicted secondary structure of the wild-type EBER2 RNA. The 5'3' stem ("S"), and the two loops ("LI", "L2"), as well as the Xmal cloning site used to construct the EBER2-L2 mutant are indicated. b. Alternate predicted secondary structures for the EBER2-L2 RNA are illustrated. Labeling as in (a). Both structures differ minimally in their free energy $(\Delta G=3.1$ kJ). c. Northern blot analysis of transfected HEK293 cells confirming the expression of both EBER2 constructs at comparable levels.

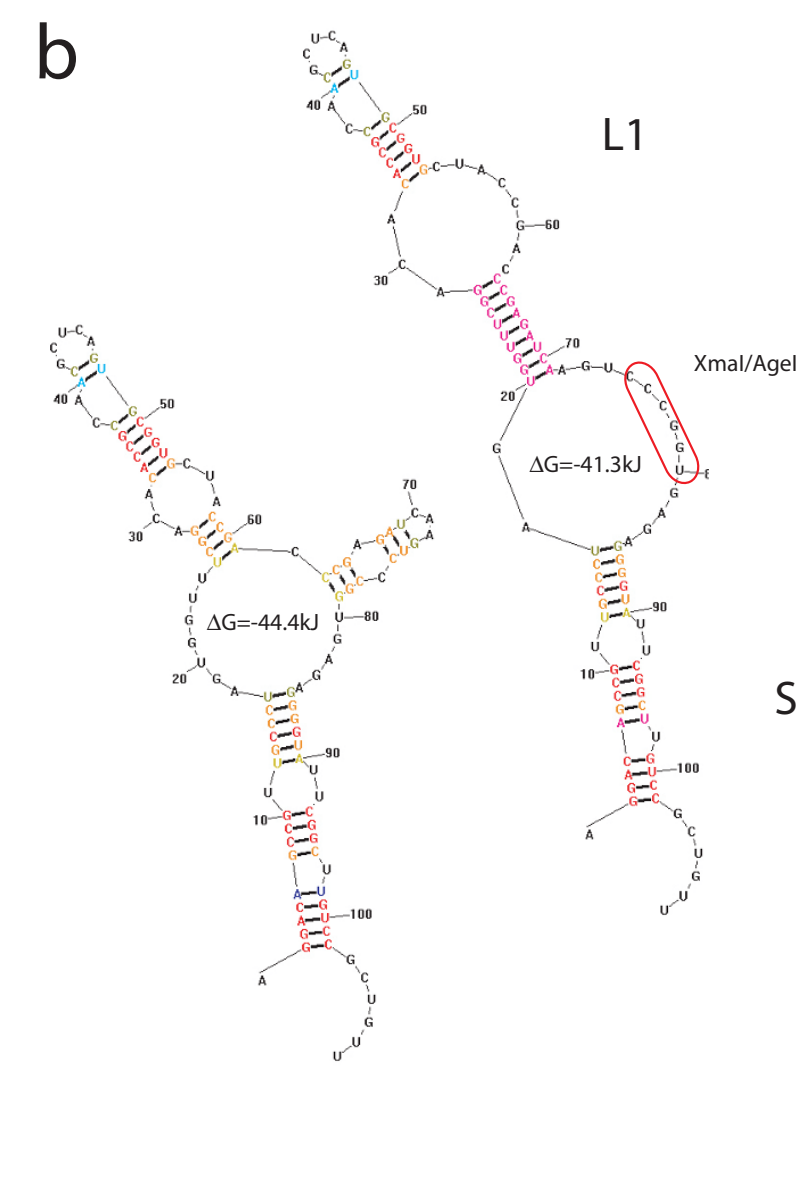

assess transcriptome changes following expression of EBER2 in HEK 293 cells.

\section{Results and discussion}

To obtain an EBER2 wild-type expression plasmid the complete gene sequence including all polIII expression elements from -156 to +195 was cloned into pUC18. Since EBER backbones have been proposed as vehicles for EBER2 expression plasmid lacking the entire loop 2 (EBER2-L2) by introducing an AgeI restriction site at position +142 which was then restricted and religated with the naturally occurring XmaI site at position +77 (Figure 1). The secondary structures of EBER2/EBER2-L2 were calculated [24] and illustrated in Figure 1. The two alternate EBER2-L2 structures differ in their free energy by $3.1 \mathrm{~kJ}$, and retain the entire $5^{\prime} 3^{\prime}$ stem structure (S) as well as the entire or the upper part of the loop 1 (L1). Both constructs expression of short hairpin RNAs [23], we constructed an 
express similar amounts of RNA as confirmed by northern blotting using a specific ${ }^{32} \mathrm{P}$-labelled antisense RNA probe that cross-hybridizes with both (Figure 1C).

First, we verified the absence of effects on cellular growth or organization during ectopic expression of the RNAs. Vectors that co-express EBER2/EBER2-L2 RNAs and green fluorescent protein (GFP) were generated by inserting the EBER2 constructs into the EcoO109I restriction site of peGFP-N1 vector (Clontech). HEK293 cells cultured in DMEM (Sigma) supplemented with $10 \%$ (v/v) Fetal Bovine Serum (Bio West) at $7 \% \mathrm{CO}_{2}$ and $37^{\circ} \mathrm{C}$ were transfected using FUGENE-HD (Roche), and GFP positive cells ( $\sim 80 \%)$ were counted daily. Nuclei were stained with Hoechst 33342 (Invitrogen), and Anti-Fibrillarin antibody (ab5821, Abcam) was used as a marker for nucleoli by immunostaining of Fluoromount-G mounted cells. Neither analysis revealed significant differences when comparing EBER2, EBER2-L2 and mock (GFP only) transfected cells (Figure 2). We also were not able to detect any other significant changes in the morphology of the HEK293 cells upon EBER2 expression.

For microarray analysis, HEK293 cells were transfected with pUC18 vector or the EBER2/EBER2-L2 constructs by calcium phosphate co-precipitation technique using the initial constructs to avoid secondary effects by the coexpression of GFP. Total RNA was extracted $48 \mathrm{~h}$ posttransfection with an RNeasy Midi Kit (Qiagen), and analyzed for quality with an Agilent 2100 Bioanalyser. RNA amplification, labeling, hybridization and detection were done following the protocols supplied by Applied Biosystems using $2 \mu \mathrm{g}$ of total RNA as input. Labeled cRNAs were then hybridized and detected on HGS Version 2.0 AB1700 microarrays containing probes for 29362 validated human genes. The AB1700 technology has been demonstrated to cover an increased signal dynamic range, display higher sensitivity and provide more robust gene expression estimates when compared to the leading competing technologies [25].

In this manner three independent biologic replicates (independent transfections) for the pUC18 and EBER2 plasmids, and five independent biologic replicates for the EBER2-L2 construct were generated. Expression Array System Software V1.1.1 (ProdNo: 4364137) was used to acquire the images and primary data analysis. The homogeneity of the different biologic replicates was assessed using heat-maps (Figure 3A) and average Pearson correlation coefficients calculated over the entire set of $\sim 34000$ probes (Figure 3B). All three sets of experiments were found to be highly reproducible as demonstrated by $R^{2} \mathrm{~s}$ of at least 0.92 , with $75 \%$ of the $R^{2}$ s being even superior to 0.95 (Figure $3 \mathrm{~B}$ ). Calculation of subtraction profiles was performed according to standard procedures in an "every- one-against-everyone" scheme and log2 fold-changes ("logQ", "L") where then determined as averages of variance-weighted individual $\log Q$ values using the NeONORM method for normalization (Additional File 1; M4) with parameter $k=0.20$. P-values were determined using standard ANOVA methodology. Multiple probes for a single gene, cross-reactivity of a single probe to several genes, as well as the resolution of probe-ID annotations were according to previously defined standards (Additional File $1 ; \mathrm{M} 5$ ).

Statistically significant changes in the HEK293 transcriptome upon EBER2 or EBER2-L2 expression are observed (Figure 3A). In the former case a total of 1218 probes are found to detect differential gene expression at $\mathrm{p}<0.01$, of which 137 are stimulated, and 1081 are repressed in their expression when compared to mock (pUC18) transfected cells. Thus EBER2 expression has a significant impact on the cellular transcriptome. Likewise, the EBER2-L2 has a very pronounced effect on cellular transcription. A total of 6269 probes are found to return statistically significant ( $p$ $<0.01$ ) differential signals, with the vast majority of genes being repressed in their expression (6230 probes). Comparisons of both target gene sets (Additional Files 2, 3) reveal that out of the 1218 EBER2 targets 962 (or 79\%) are also found to be EBER2-L2 targets (Venn-Diagrams, Figure 3A; Additional File 4). The clear majority of genes specific to EBER2 are up-regulated in their expression indicating that positive transcription regulation requires integrity of, and may be dependent directly on the L2 structure. The important number of genes negatively affected in their transcription by EBER2-L2 is believed to be a consequence of functionally unproductive titration of cellular components leading to global repression of RNA processing in the cell. Alternatively, albeit very unlikely, we can not formally rule out the possibility that EBER2 RNA or degradation products of the RNA interfere with the transcriptome activity measurements. Such findings have to be considered when using EBER2 RNA sequences as a vehicle for the expression of shRNAs, as recently proposed by Choy and colleagues [23].

Functional meta-analysis using Kegg/GO/PANTHER ontologies for emergent properties of the two target gene sets was performed using a binominal distribution and a Bonferroni multiple testing correction. The joint EBER2/ EBER2-L2 target gene set is statistically significantly ( $\mathrm{p}<$ 0.05) enriched in genes coding for components of the "cytoskeletal regulation by rho GTPase" pathway (Figure 3C). Both RHOA and RHOC coding genes, as well as CDC42 were found to be repressed across the eight independent biologic replicates when compared to the mock transfected cells, and have previously been shown to be primordial in the cellular stress response pathway [26] by orchestrating the regulation of cytoskeletal dynamics [27]. 

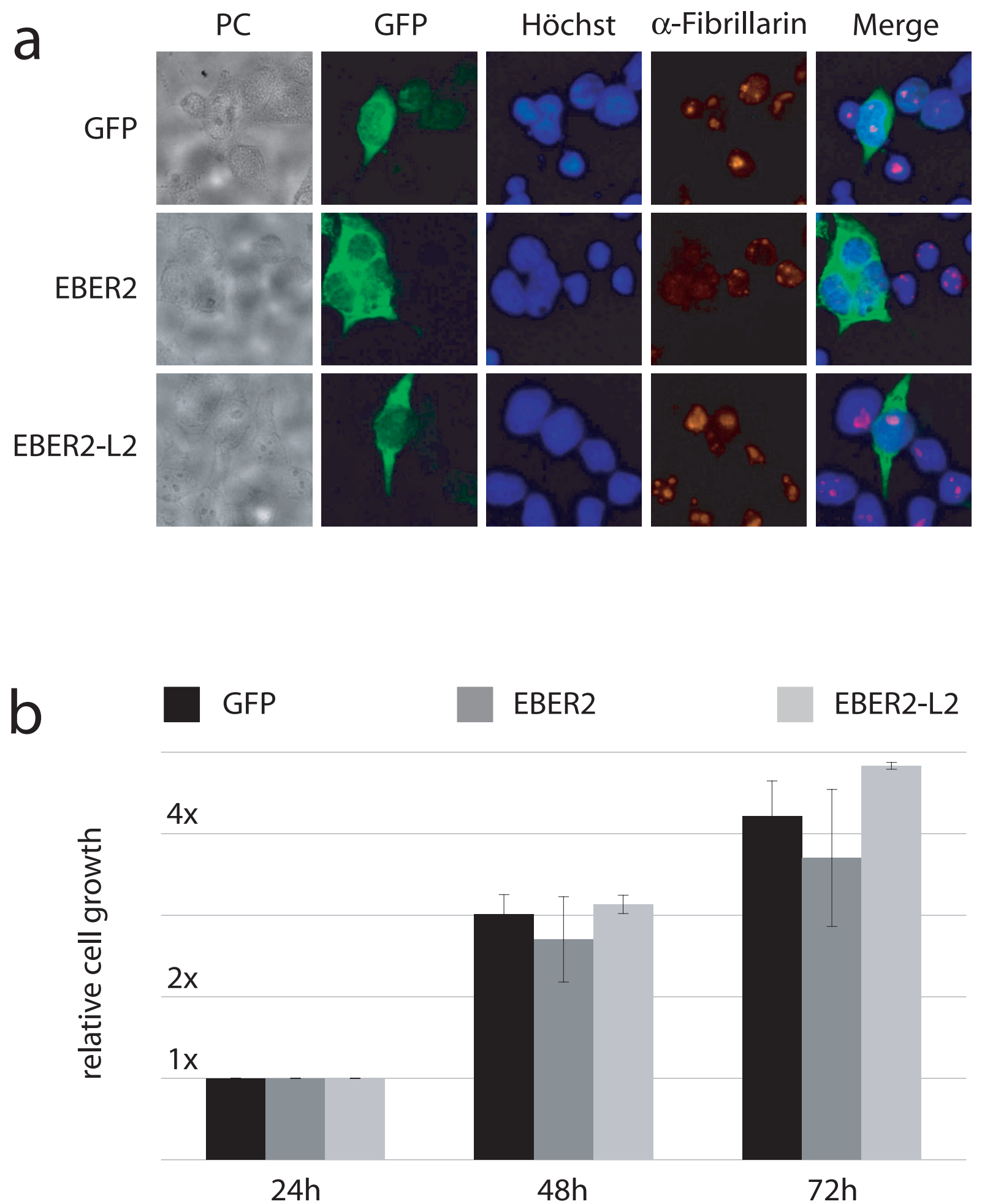

Figure 2

Absence of effects on cellular growth and subcellular organization by EBER2 expression. a. Phase-contrast ("PC"), fluorescence ("GFP", "Hoechst"), and immunofluorescence (" $\alpha$-Fibrillarin") for mock ("GFP") and EBER2 or EBER2-L2 transfected HEK293 cells. b. Growth curves for the same cells. Averages and standard deviations of at least three independent transfections are shown. 

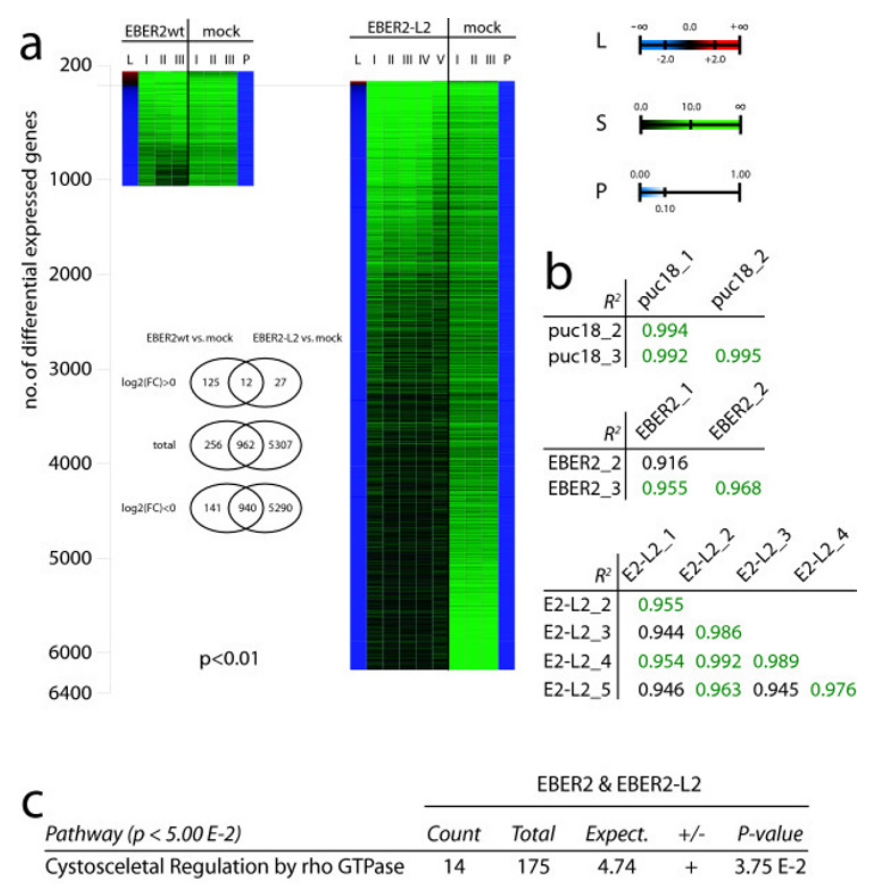

\begin{tabular}{lccccc} 
d & \multicolumn{5}{c}{ EBER2-L2 } \\
\cline { 2 - 6 } & Count & Total & Expect. & + - & P-value \\
\hline Protein Biosynthesis & 350 & 988 & 174.43 & + & $1.04 \mathrm{E}-30$ \\
mRNA splicing & 128 & 309 & 54.55 & + & $1.74 \mathrm{E}-15$ \\
Translational Regulation & 74 & 153 & 27.01 & + & $1.00 \mathrm{E}-11$ \\
Protein Folding & 104 & 271 & 47.85 & + & $1.57 \mathrm{E}-10$
\end{tabular}

\section{Figure 3}

a. Heat-maps of statistically significant $(p<0.0 I)$ changes in gene expression when comparing EBER2/ EBER2-L2 transfected to mock (pUCI 8) transfected cells at 48 h post-transfection. "L": log2(FoldChange), roman numbers indicate independent biologic replicates, "S": signal; "P": p-value. b. Average Pearson correlation coefficients of the transcriptome profiles of the biological replicates. Homogeneity and reproducibility of the independent biologic replicates was assessed using Pearson correlation coefficients averaged over the common subset of $\sim 34000$ probes. Pearson correlation coefficients larger than 0.950 have been highlighted in dark green. c. Pathway analysis of the joint set of EBER2 and EBER2-L2 target genes. "Count": number of genes corresponding to a given pathway present in the selected dataset, "Total": total number of genes associated to given pathway, "Expect.": expected number of genes given the size of the selected dataset and a random zerohypothesis, "+:-": statistical over- (+) or under- (-) representation, "P-value": likelihood of zero-hypothesis to be correct. d. Biologic Process analysis of EBER2-L2 target genes.

Nomenclature as in (b).

Concomitantly, we find other cellular components of the cytoskeleton among the EBER2 target genes, such as the actin related protein $2 / 3$ complex family members $1 \mathrm{~B}, 3$, and 5 [28], as well as the tubulin beta $2 \mathrm{~B}$ and 4 family members [29] along with other cytoskeletal components.
These data strongly suggest negative regulatory responses of the rho-pathway following EBER2 expression (Figure 4; Additional File 5).

The strong negative regulation by EBER2-L2 is explained by over-representation ( $\mathrm{p}<1.00 \mathrm{E}-9)$ of genes related to mRNA maturation and protein synthesis in this dataset (Figure 3D). EBER2-L2 likely interferes in a non-physiological manner with the production and/or assembly of the splicing and translation apparatuses, as the same processes are not overrepresented when the EBER2 target gene set is analyzed. Furthermore, both EBER2 and EBER2-L2 might be processed by the RNA editing/degradation machinery and give rise to molecules inferring with either physiological processes, or, albeit highly unlikely, the transcriptome analysis itself.

The EBER2 specific target gene repertoire also reveals down-regulation of three highly related interferon inducible trans-membrane proteins IFITM1, 2, 3, and induction of several cellular growth regulators such as FGF receptor 3 and TGF $\beta$ receptor 3 [30]. The regulation of the latter is observed only with EBER2 and therefore is directly assignable to L2 integrity (Figure 4). The main categories of EBER2 targeted genes related to cellular growth, reorganization, and stress thereby seem to coincide well with previous advances in the understanding of EBER2 biology [22]. The results here should therefore provide a novel, complementary avenue to the understanding of EBER RNAs and EBV physiopathology.

\section{Conclusion}

These investigations establish the feasibility of recording transcriptome dynamics downstream of non-translated small nuclear RNAs. Furthermore, they do not only point to a role of EBER2 in regulating the activity of cellular pathways related to growth and the cytoskeleton, as well as negative interference into interferon mediated immune responses and cellular stress, but also provide a basis for the identification of the molecular targets of EBER2 RNA and the understanding of the physiopathology of EBV, in general. Regulating the activity of growth, cytoskeletal dynamics as well as inhibition of cellular stress seems in tune with recent advances in the understanding of EBER2 biology in the context of B-cell transformation [22]. Finally, these data should also prove very helpful in the interpretation of results obtained using shRNA-EBER fusion constructs as pioneered by Choy and colleagues [23]. Given its high expression levels and structural stability, EBER2, like other pol-III transcribed and/or viral RNAs are being proposed as vehicles for the over-expression of knock-down small interfering RNA species. The fact that the backbone might, as shown here in the case of the EBER2, have profound effects on the cellular transcrip- 


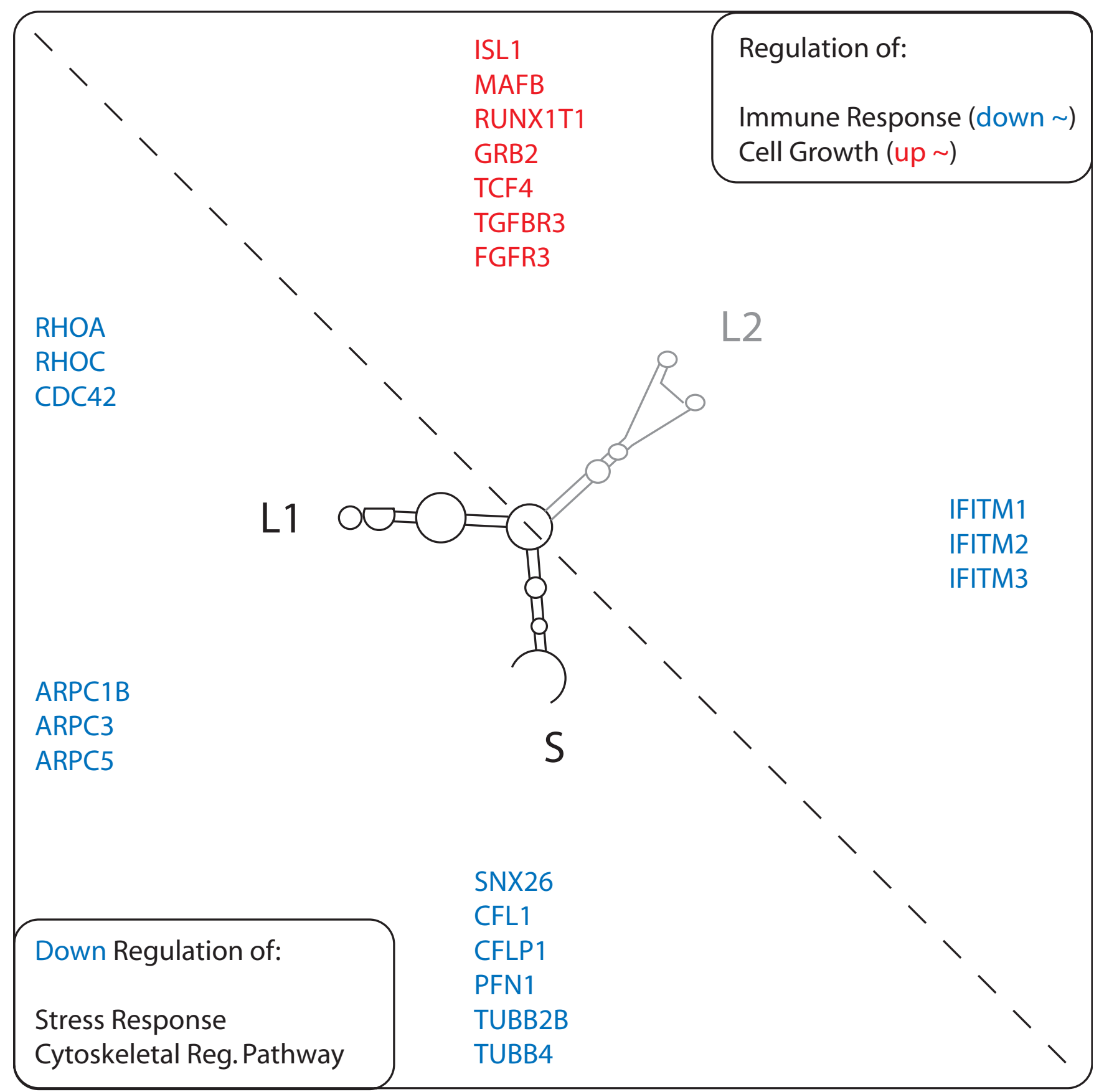

Figure 4

Schematic representation of the main results. EBER2 down-regulated genes in blue, up-regulated target genes in red. The $L 2$ is required for positive regulation of cell growth related genes and negative regulation of interferon target genes. The core $(\mathrm{S}+\mathrm{LI})$ of the EBER2 RNA targets the "cytoskeletal regulation by rho GTPases" pathway.

tome will certainly have to be studied during the validation of such hybrid molecules.

\section{Competing interests}

The authors declare that they have no competing interests.

\section{Authors' contributions}

SE has designed and generated the EBER2 expression constructs and performed the molecular and cellular biology experiments, assisted during transcriptome data generation, and contributed to the writing of the manuscript. FXP has performed the transcriptome data acquisition 
and primary, secondary, and tertiary transcriptome data analysis. PO has contributed to the molecular and cellular biology experiments as well as manuscript preparation. GB has programmed the algorithm used for the ontology meta-analysis. BJB and $\mathrm{AB}$ have designed and supervised the study, performed the biological interpretation of the data, and written the manuscript. All authors have read and approved the final manuscript.

\section{Additional material}

\section{Additional File 1}

A description of the methodology used, including additional references. Click here for file

[http://www.biomedcentral.com/content/supplementary/17560500-1-100-S1.pdf]

\section{Additional File 2}

An ascii tab-delimited text file containing the logarithmic base-two foldchange, p-value, and primary annotation for the entire set of probes revealing statistically significant changes in gene expression $(p<0.01)$. Click here for file

[http://www.biomedcentral.com/content/supplementary/17560500-1-100-S2.txt]

\section{Additional File 3}

Idem for EBER2-L2 in above format.

Click here for file

[http://www.biomedcentral.com/content/supplementary/17560500-1-100-S3.txt]

\section{Additional File 4}

The joint target gene set in above format.

Click here for file

[http://www.biomedcentral.com/content/supplementary/17560500-1-100-S4.txt]

\section{Additional File 5}

EBER2 targets from the "cytoskeletal regulation by rho GTPases" pathway.

\section{Click here for file}

[http://www.biomedcentral.com/content/supplementary/17560500-1-100-S5.txt]

\section{Acknowledgements}

F.X.P. is recipient of a fellowship from the Nausicaa Combat Sa Leucémie Association. This work was funded through support from the European Hematology Association - José Carreras Foundation, the Institut des Hautes Études Scientifiques, the Centre National de la Recherche Scientifique (CNRS), and the Région Nord (all to A.B.). A.B.'s laboratory also acknowledges funding from the Agence Nationale de Recherche sur le SIDA, and the Agence Nationale de la Recherche (ISPA, 07-PHYSIO-013-02) towards the development of transcriptome analysis methodology.

The transcriptome profiles used for this study have been deposited in the GEO database with Accession No.: GSEI 1093. The additional files are also available from the authors' website in the web sources/supplementary data section at http://seg.ihes.fr.

\section{References}

I. Epstein MA, Achong BG, Editors: The EPSTEIN-BARR Virus: Recent Advances. William Heinemann Medical Books 1986.

2. Klein G: Viral latency and transformation: the strategy of Epstein-Barr virus. Cell 1989, 58:5-8.

3. Young LS, Rickinson AB: Epstein-Barr Virus: $\mathbf{4 0}$ years on. Nat Rev Cancer 2004, 4:757-68.

4. Herrmann K, Niedobitek G: Epstein-Barr virus-associated carcinomas: facts and fiction. J Pathol 2003, I 99:|40-5.

5. Pattle SB, Farrell PJ: The role of Epstein-Barr virus in cancer. Expert Opin Biol Ther 2006, 6: I 193-205.

6. Rickinson $A B$, Kieff E: Epstein-Barr virus. In Field's Virology Volume II. Edited by: Kinpes DM, Howley PM. Lippincott Williams \& Wilkins; 2001:2575-2627.

7. Serraino D, Piselli P, Angeletti C, Scuderi M, Ippolito G, Capobianchi MR: Infection with Epstein-Barr virus and cancer: an epidemiological review. J Biol Regul Homeost Agents 2005, 19:63-70.

8. Dumpelmann E, Mittendorf $H$, Benecke BJ: Efficient transcription of the EBER2 gene depends on the structural integrity of the RNA. RNA 2003, 9:432-42.

9. Lerner MR, Andrews NC, Miller G, Steitz JA: Two small RNAs encoded by Epstein-Barr virus and complexed with protein are precipitated by antibodies from patients with systemic lupus erythematosus. Proc Natl Acad Sci USA 198I, 78:805-9.

10. Chang KL, Chen YY, Shibata D, Weiss LM: Description of an in situ hybridization methodology for detection of Epstein-Barr virus RNA in paraffin-embedded tissues, with a survey of normal and neoplastic tissues. Diagn Mol Pathol 1992, I:246-55.

I I. Bhat RA, Thimmappaya B: Two small RNAs encoded by EpsteinBarr virus can functionally substitute for the virus-associated RNAs in the lytic growth of adenovirus 5. Proc Natl Acad Sci USA 1983, 80:4789-93.

12. Glickman JN, Howe JG, Steitz JA: Structural analyses of EBER I and EBER2 ribonucleoprotein particles present in EpsteinBarr virus-infected cells. J Virol 1988, 62:902-II.

13. Howe JG, Shu MD: Isolation and characterization of the genes for two small RNAs of herpesvirus papio and their comparison with Epstein-Barr virus-encoded EBER RNAs. J Virol 1988, 62:2790-8.

14. Toczyski DP, Steitz JA: EAP, a highly conserved cellular protein associated with Epstein-Barr virus small RNAs (EBERs). EMBO J 1991, 10:459-66.

15. Fok V, Mitton-Fry RM, Grech A, Steitz JA: Multiple domains of EBER I, an Epstein-Barr virus noncoding RNA, recruit human ribosomal protein L22. RNA 2006, I 2:872-82.

16. Toczyski DP, Matera AG, Ward DC, Steitz JA: The Epstein-Barr virus (EBV) small RNA EBERI binds and relocalizes ribosomal protein L22 in EBV-infected human B lymphocytes. Proc Natl Acad Sci USA 1994, 9 I:3463-7.

17. Clarke PA, Schwemmle M, Schickinger J, Hilse K, Clemens MJ: Binding of Epstein-Barr virus small RNA EBER-I to the doublestranded RNA-activated protein kinase DAI. Nucleic Acids Res 1991, 19:243-8.

18. Clemens M]: The small RNAs of Epstein-Barr virus. Mol Biol Rep 1993, I 7:81-92.

19. Nanbo A, Yoshiyama H, Takada K: Epstein-Barr virus-encoded poly(A)- RNA confers resistance to apoptosis mediated through Fas by blocking the PKR pathway in human epithelial intestine 407 cells. J Virol 2005, 79: I2280-5.

20. Kitagawa N, Goto M, Kurozumi K, Maruo S, Fukayama M, Naoe T, Yasukawa M, Hino K, Suzuki T, Todo S, Takada K: Epstein-Barr virus-encoded poly(A)(-) RNA supports Burkitt's lymphoma growth through interleukin-IO induction. $E M B O$ J 2000, I9:6742-50.

21. Fan SQ, Ma J, Zhou J, Xiong W, Xiao BY, Zhang WL, Tan C, Li XL, Shen SR, Zhou M, Zhang QH, Ou YJ, Zhuo HD, Fan S, Zhou YH, Li GY: Differential expression of Epstein-Barr virus-encoded RNA and several tumor-related genes in various types of nasopharyngeal epithelial lesions and nasopharyngeal carcinoma using tissue microarray analysis. Hum Pathol 2006, 37:593-605.

22. Wu Y, Maruo S, Yajima M, Kanda T, Takada T: Epstein-Barr virus (EBV)-encoded RNA 2 (EBER2) but not EBER I plays a critical role in EBV-induced B-cell growth transformation. J Virol 2007, 8 I : I | 236-45. 
23. Choy EY, Kok KH, Tsao SW, jin DY: Utility of Epstein-Barr virusencoded small RNA promoters for driving the expression of fusion transcripts harboring short hairpin RNAs. Gene Ther 2008, I5:|9|-202.

24. Mathews DH, Disney MD, Childs JL, Schroeder SJ, Zuker M, Turner $\mathrm{DH}$ : Incorporating chemical modification constraints into a dynamic programming algorithm for prediction of RNA secondary structure. Proc Natl Acad Sci USA 2004, 101:7287-92.

25. Noth S, Brysbaert G, Pellay FX, Benecke A: High-sensitivity transcriptome data structure and implications for analysis and biologic interpretation. Genomics Proteomics Bioinformatics 2006, 4:212-29.

26. Tzima E: Role of small GTPases in endothelial cytoskeletal dynamics and the shear stress response. Circ Res 2006, 98:176-85.

27. Hall A: Rho GTPases and the control of cell behaviour. Biochem Soc Trans 2005, 33:89I-5.

28. Goley ED, Welch MD: The ARP2/3 complex: an actin nucleator comes of age. Nat Rev Mol Cell Biol 2006, 7:713-26.

29. Wade RH: Microtubules: an overview. Methods Mol Med 2007 137:1-16.

30. Geiger TR, Martin JM: The Epstein-Barr virus-encoded LMP-I oncoprotein negatively affects Tyk2 phosphorylation and interferon signaling in human B cells. J Virol 2006, 80: I I 638-50.

Publish with Bio Med Central and every scientist can read your work free of charge

"BioMed Central will be the most significant development for disseminating the results of biomedical research in our lifetime. "

Sir Paul Nurse, Cancer Research UK

Your research papers will be:

- available free of charge to the entire biomedical community

- peer reviewed and published immediately upon acceptance

- cited in PubMed and archived on PubMed Central

- yours - you keep the copyright 